air of the country rather than in the exhausted air of their cities.

"As was recently stated in ThE Hospital the city of Paris has decided to pull down the "Hotel Dieu" and the other old Hospitals in the city and to rebuild them on modern principles in the suburbs where space can be obtained at moderate cost.

" On the other hand, we in London continue to expend each year large sums in enlarging and adding to our present hospitals. King's College Hospital is setting a good example in deciding to remove to the suburbs, and I feel confident that in the course of a very few years both the medical profession and public opinion generally will condemn our present arrangements.

"If, therefore, instead of expending such a large sum upon extending their present site, the authorities of St. Bartholomew's had decided to spend a smaller amount in erecting an entirely new hospital somewhere on the outskirts of London, they might have devoted their present site to a new out-patient department with sufficient modernlyconstructed wards for all emergency or trivial cases. By some such arrangement they would have been able to provide for a much larger number of patients at a comparatively small outlay.

"I fully realise that any such proposal raises several difficult problems in reference to the medical staff and students, but in these days of rapid locomotion I do not believe that the difficulties are insuperable, while it is certain that patients, students, and nurses would all benefit greatly in health by the change.

“Anyone who has visited Christ's Hospital since its removal from Newgate Street to Horsham will not need any further demonstration of the benefits derivable from fresh air than is evident from the impoved appearance of the Blue Coat boys."

\section{ST. BARTHOLOMEW'S HOSPITAL NOTICES.}

WE are requested to state that a copy of the suppressed report of the Medical Council to the Lord Mayor's Committee, together with the architect's plan for reconstruction on the present site, may be obtained free on application or by post on enclosing two stamps to the Manager, The Scientific Press, 28 and 29 Southampton Street, Strand, W.C.

A Donation of $£ 2,000$ has been received from the Grocers' Company for the out-patients' department of St. Bartholomew's Hospital.

A DONATION of $£ 1,000$ has been received from the Worshipful Company of Mercers to the Building Fund of St. Bartholomew's Hospital.

\section{BELGRAVE HOSPITAL FOR CHILDREN.}

ON Tuesday, December 1st, the inauguration of the work of this hospital, which had been opened by H R H. Princess Henry of Battenberg last July, took place under the auspices of the Bishop of Rochester.

The large hall was quite filled with guests when the Bishop entered, and, after conducting a short service of dedication, made a short speech. Having alluded to the opening ceremony in July, he said that the present ceremony was of a more domestic character, and the gathering consisted of those who were more closely interested with the building, the workers themselves and their immediate neighbours. The building of this hospital was an instance of what was likely to be done on a larger scale in the future, namely, the provision of hospital accommodation on the south side of the Thames. Tais hospital was new here, but old elsewhere, it having been first established in Pimlico nearly forty years ago. He chiefly associated with that change the name of the late Duke of Westminster, who in his position was one of the first citizens of the West End of London to recognise the obligations of the West End to this home of labour on the south side of the river. What the late Duke personally recognised in a liberal and practical way was now being recognised by public opinion. The moving of this hospital was, they had a right to hope confidently, the beginning of better things, for they had now heard of the prospective moving of King's College Hospital, a step which he was heartily glad had been decided upon. With regard to the Belgrave Hospital, it was not yet complete, although $£ 40,000$ had been spent upon it. Now that they had received this noble contribution to their local life, he trusted that they would all rally round it in every way possible. The good that was done by hospitals was not confined to the actual patients treated in them but percolated throughout the whole neighbourhood. He could not promise that the promoters of the hospital would meet with much return in the way of money, for they were a very poor lot down there, but they would find a real return in gratitude and interest. He wished the hospital godspeed with all his heart and considered it a privilege to have been able to do anything in its support. Before closing his remarks he made an appeal for the right and proper provision for the spiritual needs of the nurses of the hospital. He trusted that if it was felt that they needed a chapel within the building as in other hospitals such as Guy's, that this need would be supplied by the authorities. In some of the foreign hospitals, owing to the prevalence of the non-religious and anti-religious spirit, there was no provision for the spiritual needs of the patients or the nurses who had so heavy a strain upon them. As yet this was not the case in England.

Mr. W. H. Warner, vice-chairman of the hospital, made an appeal for help towards the funds of the hospital to enable them to carry on their work.

The hospital was first opened for work on that day, and admitted two in-patients and treated 14 out-patients.

\section{THE SALOP INFIRMARY.}

AT the recent Anniversary Meeting of the Salop Infirmary, Shrewsbury, at which the Earl of Bradford presided, the following report was presented:-

The report stated that the directors had invited Sir Henry Burdett, K.C.B., to advise them as to the management and cost of the infirmary. Sir Henry Burdett's principal recommendation was to raise the rate of subscriptions giving the privilege of recommending an in-patient from $£ 11 \mathrm{~s}$. to $£ 22$. That was approved. The directors had the utmost satisfaction in announcing that a large number of subscribers of $£ 11 \mathrm{~s}$. had increased their subscriptions to $£ 22 \mathrm{~s}$, and others in like proportion; while ever since the attention of the county was directed to the real needs of the infirmary, donations and new subscriptions had been constantly coming in-a sufficient proof that the call only needed to be made to elicit a bearty response. But a word of caution and explanation was necessary lest the altogether changed appearance of the balance-sheet should be misunderstood. It would be noticed that the year, which ended with June 30 th, 1903, closed with a balance to credit of $£ 79114 \mathrm{~s}$. in place of the adverse balance of $£ 2,1120 \mathrm{~s}$. $8 \mathrm{~d}$. due to the treasurer on June 30th, 1902. That was mainly due to the directors having withdrawn $£ 2,200$ of the mortgage invested on property belonging to Shrewsbury School, in order to pay off the deficit which had been accumulating for several years past, and it must be remembered 